\title{
Desenvolvimento local participativo, rede social de suporte e ocupação humana: relato de experiência em projeto de extensão*
}

\section{Participatory local development, social network support and human occupation: experience report in extension project}

\author{
Ricardo Lopes Correia ${ }^{1}$, Marco Akerman ${ }^{2}$
}

http://dx.doi.org/10.11606/issn.2238-6149.v26i1p159-165

\begin{abstract}
Correia RL, Akerman M. Desenvolvimento local participativo, rede social de suporte e ocupação humana: relato de experiência em projeto de extensão. Rev Ter Ocup Univ São Paulo. 2015 jan./ abr.;26(1):159-65.

RESUMO: Este artigo relata a experiência exploratória e interdisciplinar de extensão universitária em desenvolvimento local participativo, pela Faculdade de Medicina do ABC, Santo André, SP na cidade ribeirinha de Araguaiana, MT. Os aportes teóricos para o trabalho foram os conceitos de redes sociais de suporte e de Ocupação Humana, e construção de ecomapa. Foi possível construir estratégias de mobilização participativa entre diversos atores da realidade local e instituição de ensino para o enfrentamento de problemáticas relacionadas ao trabalho. Concluiu-se que os aportes propostos foram relevantes na construção das estratégias locais, em que a participação ativa foi meio e fim do processo. Possibilitando oportunidade para processos educativos e transformadores da realidade tanto da comunidade local, quanto da crítica e intervenção para questões sociais na formação em saúde.
\end{abstract}

DESCRITORES: Desenvolvimento local; Relações comunidadeinstituição; Terapia Ocupacional/tendências, Universidades.
Correia RL, Akerman M. Participatory local development, social network support and human occupation: experience report in extension project. Rev Ter Ocup Univ São Paulo. 2015 jan./ abr.;26(1):159-65.

\begin{abstract}
This article recounts an exploratory and interdisciplinary experience of university extension in participatory local development, of the Faculdade de Medicine do ABC, Santo André, $S P$ in the riverside town of Araguaiana, $M T$, in which the contributions of work were social networks of support through device ecomap, and Human Occupation. Produced a field of participatory mobilization strategies between different actors of the local reality and educational institution for dealing with issues related to work. It was concluded that the proposed investments have important relevance in the construction of local strategies, in which the active participation was middle and end of the process, and occupational therapy, in representation of the course of the institution and the coordinator of outreach activity possible opportunity to educational processes and transforming reality of both the local community as critical for intervention and social issues in health education of the institution.
\end{abstract}

KEYWORDS: Local development; Institution-community relations; Occupational therapy/trends; Universities.

\footnotetext{
* Este artigo compõe um dos resultados da conclusão de mestrado em ciências da saúde/saúde coletiva - Uso do ecomapa para análise de redes sociais egocentradas: estratégia para o desenvolvimento local participativo. Faculdade de Medicina do ABC, Santo André, 2014.

1. Terapeuta Ocupacional; Mestre em Ciências da Saúde; Professor do curso de Terapia Ocupacional da Universidade Federal do Rio de Janeiro. E-mail: ricardo.correiato@yahoo.com.br

2. Médico Sanitarista; Professor Livre Docente da Faculdade de Saúde Pública da Universidade de São Paulo. E-mail: marco.akerman@ gmail.com

Endereço para correspondência: Rua Botucatu, 76 - fundos, Apt. 302, Grajaú. CEP: 20541-340. Rio de Janeiro, RJ, Brasil.
} 


\section{INTRODUÇÃO}

experiência relatada faz parte das ações
da Comissão de Extensão-COMEX da
Faculdade de Medicina do ABC-FMABC, localizada na cidade de Santo André, SP. Atenta às experiências da ação comunicativa com as diversas realidades sóciocomunitárias possui como eixo estruturante a dialogicidade e interdisciplinaridade.

ACOMEX conta com uma equipe de seis docentes, um discente bolsista e discentes voluntários dos cursos de Medicina, Terapia Ocupacional, Enfermagem, Fisioterapia, Ciências Farmacêuticas, Nutrição e Gestão em Saúde Ambiental.

Desde 2007 o curso de Terapia Ocupacional possui inserção nas atividades de extensão e contribui com o planejamento de ações que tomam as atividades cotidianas e a Ocupação Humana como aportes teóricos e metodológicos para o trabalho interprofissional em realidades complexas.

Para Freire ${ }^{1}$ a extensão universitária se caracteriza como um campo de práticas comunicativas entre Instituição de Ensino Superior e contexto sócio comunitário, uma relação mútua e dialógica entre diversos atores, gerando ações concretas e contextualizadas numa dada realidade social, permitindo o engajamento dos atores nas transformações de suas questões sociais.

Neste trabalho o engajamento de indivíduos e grupos em atividades da vida cotidiana, a fim de construir suportes diários para a manutenção e inventividade da própria vida, será compreendido a partir do referencial da Ocupação Humana, defendida como ação participativa ${ }^{2}$. Este ponto de vista dialoga com os objetivos do trabalho de extensão no campo de estratégias em desenvolvimento local participativo, pois se compreende que é na vida cotidiana que se expressam estruturas e valores da dimensão política macro social. As dimensões subjetivas e objetivas, marcadas por questões históricas, culturais, políticas e sociais implicam nos processos de desenvolvimento local, educativos e formativos dos atores envolvidos ${ }^{3}$.

Assim, este artigo tem como objetivo relatar a experiência de estratégias em desenvolvimento local participativo, num projeto de extensão universitária da FMABC, a partir dos aportes de redes sociais de suporte e Ocupação Humana, assim como as contribuições da Terapia Ocupacional na construção destas estratégias.

DESENVOLVIMENTO LOCAL PARTICIPATIVO: OS APORTES PARA A AÇÃO INTERDISCIPLINAR NA ATIVIDADE DE EXTENSÃO UNIVERSITÁRIA

O desenvolvimento local participativo (DLP) é um conjunto de ações estratégicas, interdisciplinares e intersetoriais, que promove a ação e o engajamento de indivíduos e seus coletivos nas transformações da realidade social local.

Para Somekh ${ }^{4}$ o DLP é um processo de inclusão social e de estratégias para melhor desconcentração territorial de capitais econômicos, sociais, culturais, intelectuais, pois age em âmbito local, a partir da contextualização de estruturas macro sociais.

O DLP, segundo Ávila ${ }^{3}$ é também o uso das capacidades humanas no seu âmbito individual e coletivo para o desenvolvimento econômico, social, cultural, intelectual e ambiental de dadas localidades.

Ávila ${ }^{3}$ compreende as capacidades humanas como conjunto articulado de atitudes, valores, habilidades, talentos e potências que são construídas na relação com as histórias de vida de cada indivíduo e de seu coletivo em dado contexto e ambiente.

O uso das capacidades para $\mathrm{Sen}^{5}$ ocorre no uso possível das capacidades para eliminar barreiras sociais, culturais, atitudinais, políticas e arquitetônicas que restringem a expansão da participação de indivíduos e coletivos aos bens produzidos na sociedade. Quanto maior o uso das capacidades maior é a percepção sobre redes de oportunidades e assim, maior é a experiência de liberdade.

O lugar social das pessoas envolvidas no contexto e o modo como fazem uso do seu ambiente pode ser estratificado e hierarquizado, o que implica negativamente no desenvolvimento local.

Queremos um desenvolvimento local com inclusão social, em que haja cooperação, criação e alargamento de esferas públicas, em que diferentes atores políticos, econômicos, sociais dialoguem de maneira transparente a partir de seus próprios interesses em conflito, buscando construir um novo desenvolvimento local em conjunto ${ }^{4}$.

Segundo Somech ${ }^{4}$ o DLP propõe o encontro entre os atores locais, públicos e privados, civis e jurídicos, de forma estratégica, para promover o diálogo sobre a realidade e enfrentamento de questões sociais por meio da participação ativa de todos os envolvidos.

Dada a complexidade dos fenômenos humanos, Akerman $^{6}$ argumenta que as estratégias em DLP devem ser multifacetadas e não direcionadas em disciplinas rígidas; o uso de instrumentos multidisciplinares que facilitem o processo em DLP em ações interdisciplinares e transdisciplinares configura-se no campo das estratégias, facilitando e dimensionando à todos os envolvidos, clareza e objetividade nas demandas sociais que possuem potenciais 
de mudanças.

Ávila ${ }^{1}$, Somekh $^{4}$ e Akerman ${ }^{6}$, compreendem que nas ações estratégicas em DLP os atores sociais vivenciam produções relacionais, que permitem aproximações e distanciamentos entre sujeitos e modos de participação com a realidade local.

O engajamento ativo em atividades do dia a dia, para participar da realidade social, é compreendido aqui como Ocupação Humana. Que para Córdova é uma prática social, para criar relações e estruturas de sobrevivência, manutenção e inventividade na vida; isso se dá pelo fazer constante de atividades num pano de fundo histórico, político e cultural, que é o cotidiano.

Até os expostos aqui, proponho que as ocupações não são algo exterior aos sujeitos, uma expressão fenomênica da interioridade das pessoas, um método para alcançar a essência através desta aparência chamada ocupação. As ocupações são práticas sociais, relacionais e, nelas mesmas, se constituem e produzem os sujeitos. Não há ocupação que tenha existência por si mesma. Toda a singularização é a manifestação em um sujeito, dentro de um campo ocupacional de caráter relacional (p.24) ${ }^{4}$.

A Ocupação pode ser colocada como objeto de investigação no trabalho em desenvolvimento local. Para isso, a ferramenta rede social de suporte, pode ser utilizada para o registro das participações individuais e coletivas.

Para Marques ${ }^{7}$ redes sociais de suporte, é a sistematização de experiências estruturais e simbólicas construídas cotidianamente, tecidas por pessoas, atividades e lugares, tendo por finalidade o oferecimento de apoio/ suporte social.

Para Lemieux e Ouimet ${ }^{8}$ a rede social de suporte, como ferramenta, é um conjunto de estruturas sociais para a sustentação cotidiana, apoios materiais e imateriais formados e acionados pelas pessoas, a partir dos padrões relacionais percebidos ao longo da vida.

Em adição o ecomapa é uma plataforma para o trabalho com indivíduos e famílias no enfrentamento de questões relacionadas a rede social de suporte ${ }^{10}$, apresentando-se como ferramenta de análise e intervenção em redes sociais de suporte. Proposto em 1976 pela professora e Assistente Social da Michigan University Ann Hartman se configura como diagrama para identificar redes e agenciar raciocínio mutuo, entre sujeito da atenção e profissional, o desenvolvimento de tomadas de decisão e intervenção.

Segundo Correia ${ }^{9}$ o ecomapa é construído por meio de narrativas sobre a participação do sujeito em seu cotidiano. As narrativas são transcritas por códigos, que facilitam a tomada de percepção sobre a rede social de suporte. A estrutura do ecomapa é feita por um círculo central, indivíduo, família ou qualquer outro grupo social, e círculos radiais, que são as estruturas sociais da rede pessoas, lugares e atividades (Figura 1).

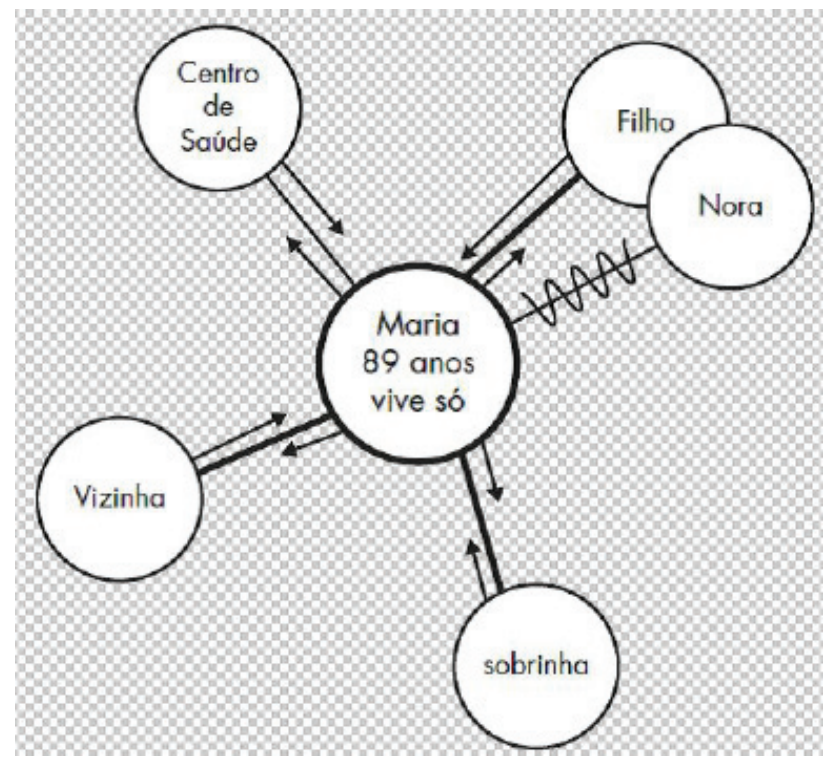

Fonte: Agostinho apud Correia ${ }^{9}$

Figura 1 - Diagrama ecomapa

\section{ACONSTRUÇÃO DAEXPERIÊNCIADE EXTENSÃO EM DESENVOLVIMENTO LOCAL PARTICIPATIVO}

A experiência de extensão em desenvolvimento local participativo na cidade de Araguaiana iniciou-se em 2011, em parceria da Comissão de Extensão - COMEX/FMABC e a ONG Amazonas Visão ${ }^{(1)}$ para levar equipe multidisciplinar e estudantes de graduação ${ }^{(2)}$ para prestação assistência em saúde, social e educação ambiental à população ribeirinha do norte e nordeste do Brasil, sob a coordenação de um professor do curso de Terapia Ocupacional.

Araguaiana é uma cidade ribeirinha, localizada no centro oeste do estado do Mato Grosso, possui 216.429

(1) A ONG Amazonas Visão é uma organização social sem fins lucrativos, formada por profissionais médicos de diversas cidades do Brasil que prestam serviços especializados no norte e nordeste.

(2) Na época a equipe constou com dois alunos de graduação em Medicina e Terapia Ocupacional e um aluno dos respectivos cursos de Enfermagem, Ciências Farmacêuticas, Nutrição, Fisioterapia e Gestão em Saúde Ambiental, totalizando 9 discentes. 
$\mathrm{Km}^{2}$ e uma população de 3.112 habitantes. Banhada pelo rio Araguaia, a cidade possui economia centrada na pesca e agropecuária ${ }^{10}$.

Durante cinco meses do ano, de março a agosto, ocorre o fenômeno da piracema, caracterizado pela crescente do rio Araguaia, inundando regiões de produção agrícola; neste período a pesca é proibida por conta da fase de desova de diversas espécies de peixes.

A equipe de extensão permaneceu na cidade durante oito dias. No primeiro dia foi realizado contato com o prefeito e alguns secretários e levantados os principais problemas locais, como: fragilidade nas oportunidades de trabalho, uso abusivo de álcool entre adolescentes e a escassez de recursos para atividades de lazer.

Realizaram-se visitas em sete bairros da cidade, sendo três deles bairros rurais e uma fazenda, acompanhadas por Agentes Comunitários de Saúde (ACS) da Estratégia de Saúde da Família (ESF) e Agentes Sociais (AS) do Centro de Referência em Assistência Social (CRAS). As visitas tiveram por objetivo a aproximação da equipe com os principais serviços e estruturas sociais da cidade, como escolas, praças, urbanismo, regiões agrícolas e pesca, tendo duração média de 8 horas.

A equipe reuniu-se para o planejamento de ações, a partir dos pressupostos do DLP, formulou-se uma pergunta disparadora para o trabalho: Qual seria a percepção dos moradores sobre os modos de participação na rede social de suporte da cidade de Araguaiana?

A partir desta pergunta, organizaram-se ferramentas prévias para o diálogo com a comunidade, com utilização do ecomapa, para registro das narrativas. Assim, no segundo dia a equipe se organizou em duplas: um membro da equipe e um ACS ou AS para realizar Visitas Domiciliares (VD).

Nas VDs as famílias eram convidadas a participar, no dia seguinte, de uma roda de conversa, a fim de discutir os temas de estruturas sociais identificadas no ecomapa.

Foram realizadas 96 VDs e ecomapas, e as informações coletadas foram posteriormente tabuladas pela equipe de extensão e construído um ecomapa representativo (Figura 2) sobre as percepções identificadas na rede social de suporte da cidade de Araguaiana e servir como ferramenta de mediação e discussão coletiva na roda de conversa ${ }^{(3)}$.

Para a realização da roda de conversa, a equipe elegeu uma escola municipal da cidade, identificada no primeiro dia de trabalho, pois se encontrava num ponto central e de fácil acesso aos moradores dos diversos bairros em que as VDs foram realizadas.

Representantes do poder público local e trabalhadores de diversos segmentos compuseram a roda, totalizando 32 participantes. A estrutura para a roda de conversa foi organizada da seguinte forma: 1) apresentação dos participantes, 2) contextualização do trabalho de extensão em DLP, 3) apresentação do ecomapa representativo, 4) debate sobre as percepções da rede e 5) agendamento local, totalizando uma hora e trinta minutos.

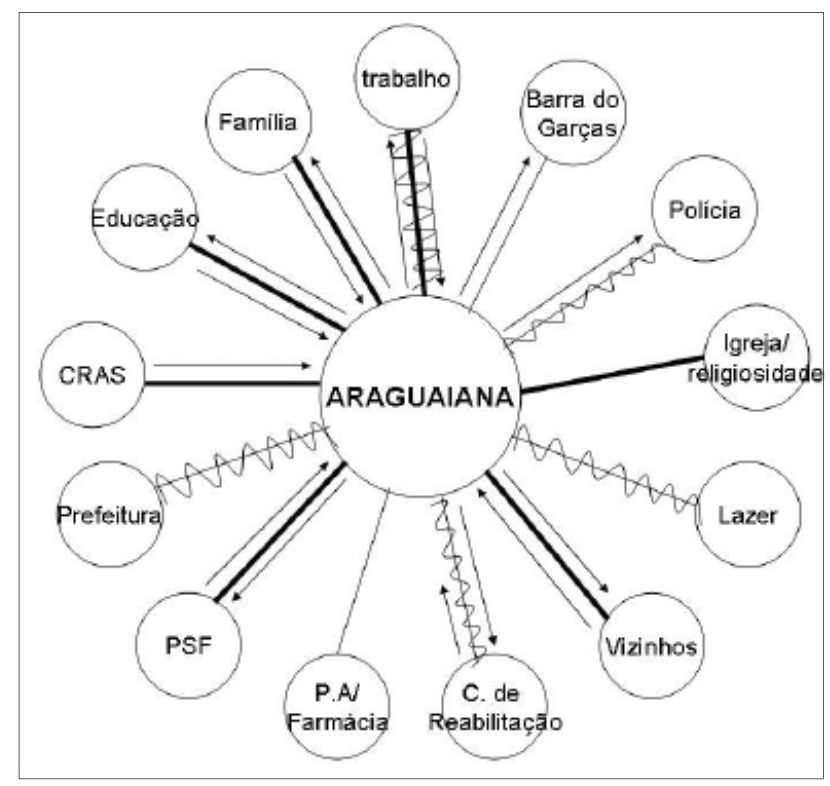

Fonte: Correia ${ }^{9}$

Figura 2 - Ecomapa representativo de Araguaiana

Para Schwartz ${ }^{11}$ a roda de conversa se constitui como dispositivo comunicacional nas estratégias de DLP, aproximando os atores locais, a fim de debater temáticas sobre as questões da realidade social. Na roda é necessário que o facilitador use de dados construídos em experiências com os próprios participantes e relacione-os com temáticas de ordem macro sociais, como as Políticas Sociais, Culturais, Econômicas, possibilitando a aproximação e a ampliação de percepções e possibilidades de enfrentamento.

Estratégias de resolubilidade já estavam sendo encaminhadas pelos membros, porém sem que os mesmos soubessem, e desta forma, a roda tencionou a discussão sobre soluções coletivas intersetoriais com a participação ativa entre poder público e sociedade civil.

Segundo Ávila ${ }^{3}$ o encontro entre pessoas, de diferentes papeis e lugares sociais, se constitui como um processo educativo e formativo - a tríade: encontro, diálogo e ferramentas, é um potente mecanismo para as estratégias em DLP. 
Com isso, o facilitador da roda de conversa coordenador da equipe (Terapeuta Ocupacional) ajudou os participantes a eleger estruturas do ecomapa que pudessem ser priorizadas estrategicamente para a construção de um processo de trabalho resolutivo das questões da rede; fixouse um pequeno mural e o facilitador escrevia as decisões do grupo, através de votação. Esta estratégia é o agendamento $\mathrm{local}^{4}$, na qual foram elencadas as estruturas sociais de trabalho e lazer.

Conflitos identificados nestas estruturas tiveram importância radical no desenvolvimento da cidade de Araguaiana em decorrência do fenômeno da Piracema, quando o trabalho da pesca, a manutenção de pastos para gado e a agricultura, e as atividades de lazer das famílias, mostraram-se fragilizadas.

Ao final a equipe propôs que os moradores pudessem retornar no dia seguinte para dar continuidade. No quarto dia, foi retomado o agendamento local e passou-se a discutir quais estratégias de ação seriam necessárias para a resolução das questões das estruturas de trabalho e lazer.

Representantes dos pescadores relataram que uma estratégia organizada há quatro anos para lidar com a fragilidade do trabalho foi à construção de uma cooperativa de pescadores e pescadoras. Estes reservavam vinte por cento de suas vendas para ter assegurados uma renda auxílio durante a Piracema. Porém, o valor era variável e não atingia quantia suficiente para que mantivessem condições básicas de consumo, tendo que migrar temporariamente para outras cidades em busca de outras oportunidades de trabalho.

Constatou-se a situação de vulnerabilidade em relação ao trabalho com estratégias locais insuficientes. Outra estratégia encontrada pelos pescadores foi enviar os filhos, acima de 18 anos, à cidade de Barra do Garça para conseguir trabalho. Estes jovens deixavam suas casas e famílias e passavam a se estabelecer naquela cidade. Muitos abandonavam os estudos ao final da oitava série não conseguindo vaga em outras escolas na cidade de migração, uma vez que a cidade também não dispunha de oportunidades suficientes de trabalho, deste modo os jovens retornavam para Araguaiana sem trabalho e estímulo para estudar. O que para outros membros da cidade, era um fator determinante pela grande concentração de jovens nos bares e o uso abusivo de álcool.

Outra discussão importante foi a da não relação direta entre prefeitura e cooperativa de pescadores, e o desconhecimento de procedimentos legais para uma parceria.

A Prefeitura, que para os membros locais deveria ser uma das portas de acesso para as demandas da comunidade, apresentava-se no ecomapa com vínculo enfraquecimento e conflituoso, não havendo níveis de investimento. Sendo uma fala constante dos membros, que na prefeitura "não havia lugar para os mais desfavorecidos" e o lugar do "não direito".

Para Freire ${ }^{1} \mathrm{o}$ elemento básico na mediação entre opressores e oprimidos é a prescrição da consciência e dos comportamentos que são dados de modo alienador, sem quaisquer formas de diálogo e aproximação, fixando-se um certo lugar social sem questionamento, somente aceitação. Ambos os lados da relação, opressor-oprimido vivenciam alienações e desconhecimentos sobre si e a realidade que os formam.

Ainda no quarto encontro um jovem se propôs a conduzir a escrita das estratégias, passando a ocupar um lugar de liderança, uma vez que teve que organizar as falas e possibilitar espaço de expressão e argumentação de todos. O jovem não estava na primeira roda de conversa, seu pai era pescador e a família sofria com os mesmos problemas da renda complementar. O jovem foi para Barra do Garça, retornou após dois meses, pois não se adaptou a cidade; propôs ao pai que juntos vendessem sua produção de alfaces no centro da cidade, porém o pai não concordou, pois não vislumbrava possibilidades de comercialização.

O jovem propôs aos moradores que se todos se reunissem para vender hortifrúti fresco, das plantações de quintal, junto a outras produções domésticas, poderiam organizar uma pequena feira.

Os demais participantes entusiasmaram-se com a ideia e definiram o seguinte objetivo em relação a estrutura trabalho: construir uma feira livre aos finais de semana, em período quinzenal, no centro da cidade.

Em seguida o jovem, com apoio da equipe de extensão, facilitou a construção das estratégias para a condução do objetivo: (1) identificar as famílias e suas produções na cidade; (2) levantar famílias interessadas na participação da feira; (3) organizar encontros para construir cronograma e limitação de espaço físico; (4) organizar tarefas da feira; (5) eleger líderes para o diálogo com o poder público e (5) divulgação.

Em seguida, os participantes decidiram focalizar somente no trabalho, pois seria esta, uma primeira ação coletiva. Uma profissional Enfermeira da ESF propôs o uso do ecomapa para identificar e registrar as atividades produzidas pelos moradores, e após o levantamento das atividades, usar o ecomapa para discutir, em rodas de conversa, os interesses, organização e tarefas.

Houve apropriação dos moradores pelas estratégias de trabalho utilizadas pela equipe de extensão. Somekh ${ }^{4}$ diz que este tipo de proposição em DLP modifica as bases estruturais políticas, no que diz respeito às práticas 
assistenciais.

O hiato entre as políticas de desenvolvimento e as ações coletivas no cotidiano, pode ser preenchido pela criatividade de uma política menos burocrática, mais simplificada e fruto da participação ativa dos envolvidos em um âmbito local.

Valorizar estratégias de participação ativa em DLP, como propõe Ávila ${ }^{3}$, permite que os participantes tenham oportunidade de vivenciar suas capacidades na identificação de situações problemas, avalia-las, eleger prioridades, planejar estratégias de resolução e implementação com metas, e conseguir ao passo o reconhecimento mútuo como sujeitos participativos nas mudanças sociais, sendo estas, as verdadeiras ferramentas para a expansão das oportunidades.

Nos dias seguintes, quinto e sexto, a equipe de extensão acompanhou e facilitaram as visitas dos membros, a maioria adolescentes, nas casas de moradores, identificando, por meio das narrativas e registros no ecomapa, suas produções, como: hortaliças, artesanato, doces em compotas e vestuário.

No sétimo dia, quinze novos moradores locais participaram da roda de conversa, para dialogar sobre a construção da feira e suas estratégias, que foi conduzida pelo jovem e por mais duas pessoas, um líder religioso que ofereceu o espaço do salão da igreja presbiteriana para o encontro e uma professora de ensino infantil, que além da condução da roda, ficou responsável por divulgar e mediar a relação com o poder público, garantindo a participação de algum representante na construção das atividades.

No oitavo dia, os moradores se organizaram para escrever um projeto e um meio de comunicação entre todos os envolvidos, inclusive com a equipe de extensão, para continuar oferecendo apoio nas atividades.

A equipe não conseguiu acompanhar as demais rodas de conversa, por limites institucionais e fim da parceria entre FMABC e ONG Amazonas Visão, entretanto outras aconteceram com as lideranças, e passados quase quatro anos desde a chegada à cidade de Araguaiana, a feira tornouse realidade e é mantida quinzenalmente pela participação de 23 membros.

Outro ganho importante da expansão das capacidades dos moradores, foi o ingresso de duas jovens

\section{REFERÊNCIAS}

1. Freire P. Pedagogia do oprimido. 50a ed. Rio de Janeiro: Paz e Terra; 2011.

2. Córdova AG. Enfoque y práxis en terapia ocupacional. no curso de Administração e Pedagogia, em uma faculdade na cidade de Barra do Garça, ambas retornavam aos finais de semana para Araguaiana para ajudar em capacitações de empreendedorismo, gestão e cooperativismo social, assim como a alfabetização e complemento escolar de jovens e adultos que fazem parte do grupo de trabalhadores da feira livre e da cooperativa de pescadores.

\section{CONSIDERAÇÕES FINAIS}

O trabalho em Desenvolvimento Local Participativo, tendo a rede social de suporte e a Ocupação Humana como aportes, mostrou-se relevante dispositivo nas formas de produzir mobilizações sociais mais dialógicas, participativas e compartilhadas. Havendo grande preocupação para construir coletivamente uma prática social e comunicativa.

O envolvimento do poder público ainda foi incipiente, uma vez que a comunidade, tomando parte do poder e percepções de suas redes sociais de suporte colocavam em tensão o próprio poder público e deslocava a verticalidade da relação opressores-oprimidos e do não direito social.

A inserção do raciocínio e o modo de operacionalizar a realidade cotidiana e a participação ativa sobre as bases das atividades de vida diária foram aportes fundamentais para as intervenções compartilhadas com os atores. Sendo a Ocupação Humana uma importante contribuição que a Terapia Ocupacional ofereceu e vem oferecendo às atividades de extensão no campo do desenvolvimento local participativo e para as transformações no ensino de saúde com vistas às questões sociais.

As estratégias foram guiadas sutilmente pelos empréstimos entre saber técnico e saber cotidiano; apresentado e refletido, e quando questionado por todos, horizontalizaram as relações, equiparando um espaço de troca; e quando tomado como consciência e fator de sentido, passou a ser apropriado pelos próprios atores locais, reproduzindo de forma criativa o seu uso. E enquanto resultado das ações em DLP, houve a ampliação da percepção e uso de estruturas sociais, deixando marcadamente presente uma rede de oportunidades, de participação e liberdades.

Reflexiones desde una perspectiva de la terapia ocupacional crítica. In: Montes Bernardo S, Esmero de Iglesias C, Touceda Rey C, compiladores. Ocupación, cultura y sociedad, 
compromiso de la terapia ocupacional [monografia]. TOG (A Coruña). 2012;9(monogr. 5):18-29. Disponível em: http:// www.revistatog.com/mono/num5/mono5.pdf.

3. Ávila VF. Pressupostos para a formação educacional em desenvolvimento local. Rev Int Desenv Local - Interações. 2000;1(1):63-76.

4. Somekh N. A construção social da cidade: desenvolvimento local e projetos urbanos. In: Dowbor L. Pochmann M, organizadores. Políticas para o desenvolvimento local. São Paulo: Fundação Perseu, Abramo; 2008.

5. Sen A. Desenvolvimento como liberdade. São Paulo: Companhias das Letras; 2000.

6. Akerman M. Saúde e desenvolvimento local: princípios, conceitos, práticas e cooperação técnica. 2a ed. São Paulo: Hucitec; 2005.

Recebido para publicação: 02/01/2014

Aceito para publicação: 26/11/2014
7. Marques, Eduardo. Redes sociais e segregação e pobreza. São Paulo: UNESP/Centro de Estudos da Metrópole, 2010.

8. Lemieux V, Ouimet M. Análise estrutural das redes sociais. Lisboa: Instituto Piaget/Epistemologia e Sociedade; 2004.

9. Correia R, Lopes. O uso do ecomapa para análise de redes sociais de suporte egocentrada: estratégia para o desenvolvimento local participativo [Dissertação]. Santo André: Faculdade de Medicina do ABC, Fundação ABC; 2014.

10. Instituto Brasileiro de Geografia e Estatística (IBGE). Cidade (a): Araguaiana - dados de 2011 [citado 15 set. 2013].

11. Schwartz G. Arranjos comunicativos locais (ACLs) e desenvolvimento local. In: Dowbor L, Pochmann M, organizadores. Políticas para o desenvolvimento local. São Paulo: Fundação Perseu, Abramo; 2008. 